\title{
Une histoire de la révolution égyptienne
}

Écrit par : Anne-Lise Prigent, L'Observateur de l'OCDE

Dernière mise à jour : 21 novembre 2018

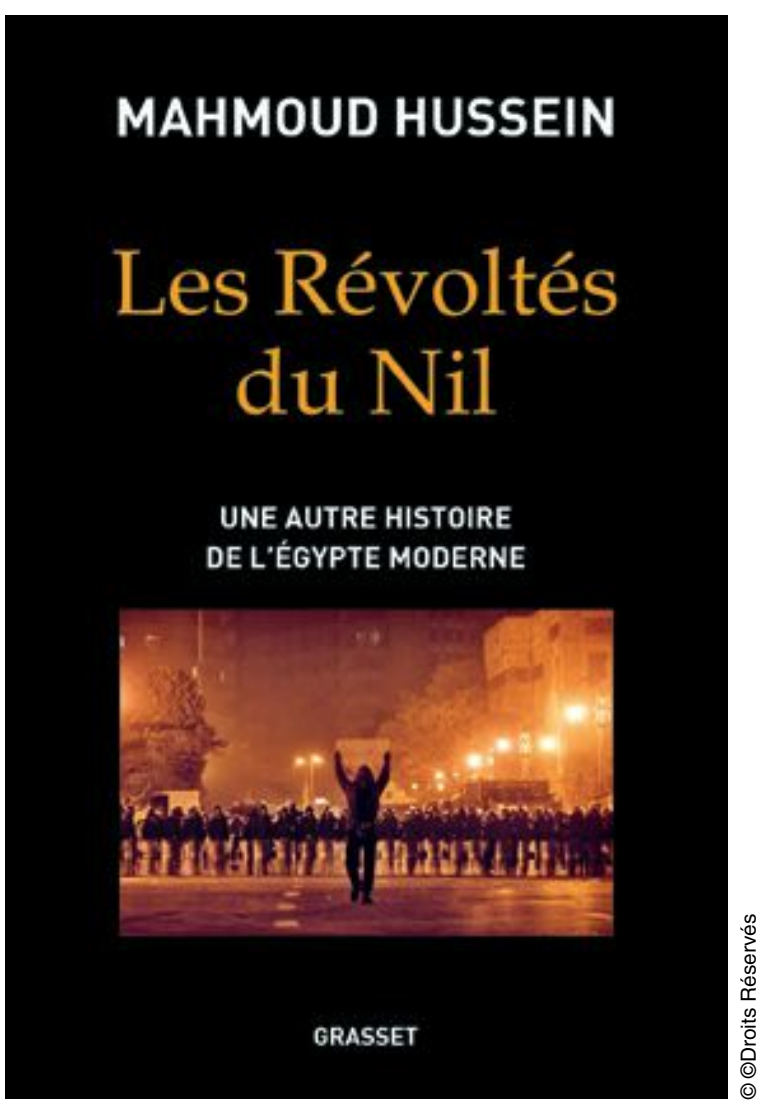

Pour bien comprendre la révolution égyptienne de 2011, il faut voir en celle-ci le point d'orgue d'une série de révoltes qui ont jalonné la longue histoire de ce pays. Depuis cet angle, nous pouvons mieux appréhender l'acquisition progressive d'un libre arbitre et d'une conscience sociale.

Les révoltés du Nil : Une autre histoire de l'Égypte moderne se lit comme un roman policier. Il est intéressant de noter que l'auteur a adopté le point de vue du peuple pour relater l'histoire mouvementée de l'Égypte depuis la fin du XVIIIe siècle, dans un fascinant exposé retraçant la naissance d'une conscience sociale populaire.

Des pharaons aux sultans, l'obéissance des Égyptiens au pouvoir était absolue et même sacrée car elle venait du ciel. L'individu n'existait pas. L'insurrection contre 
Napoléon a ouvert une première brèche : ce conflit existentiel coïncidait avec la découverte d'un nouveau modèle, séculaire et européen.

Mais les puissances occupantes se sont succédé, du bref retour des Ottomans et des Mamelouks en 1801 à l'occupation britannique qui suivit la recréation de l'État égyptien sous Méhémet Ali et Ismaill Pacha.

Face à l'ordre colonial, le soulèvement patriotique de 1919 était un moment magique, qui n'appartenait qu'au peuple, raconte Mahmoud Hussein. Qu'arrivera-t-il à cette conscience de soi à peine éclose ? Au fil des pages, le lecteur découvre qu'elle sera rapidement arrachée au peuple, une nouvelle fois. De l'arrivée au pouvoir de Nasser, en 1956, à la chute de Moubarak, en 2011, c'est la tumultueuse histoire d'une conscience patriotique puis sociale qui se déploie dans ces lignes.

Après un mouvement sans précédent, le régime de Moubarak a été renversé, sans violence, en seulement trois semaines. Pour le peuple, les gouvernants ne sont désormais que des agents administratifs désacralisés tenus de rendre des comptes. Place Tahrir, au Caire, cet incroyable soulèvement populaire a libéré la conscience collective. " Chacun en son nom énonçait une vérité universelle. » Qu'est-il arrivé à cette vague d'espoir collective ? Cet ouvrage captivant nous donne les clés de l'histoire.

@ L'Observateur de l’OCDE n³16, T4 2018

\section{Références}

Hussein, Mahmoud (2018), Les révoltés du Nil : Une autre histoire de l'Egypte moderne, Grasset, Paris, https://www.grasset.fr/les-revoltes-dunil-9782246790778 https://www.grasset.fr/les-revoltes-du-nil-9782246790778 